\title{
CURRENT THOUGHTS ON MICROBIAL FUEL CELLS
}

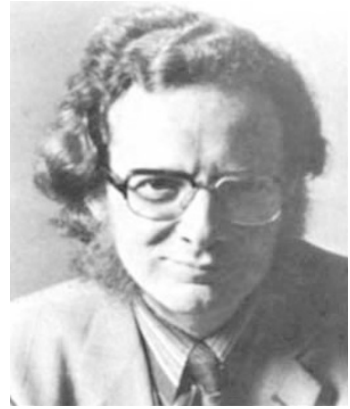
E lectric currents of more than over several hours by bacteria in a London laboratory, could be the signals which now convince even the greatest skeptics that microbial fuel cells are a practical proposition. If so, all credit to Gerard Delaney, Peter Bennetto, and their colleagues at Queen Elizabeth College. They have made this impressive performance possible by evolving an ingenious method of harnessing respiration in the bacterial cell for external power production. The economies of microbe and man have been coupled for the first time in a device that is much more than a laboratory curiosity.

Developed during the U.S. space program, conventional fuel cells capable of converting chemical energy directly to electrical energy are the descendents of a prototype assembled over a century ago by an English physicist, barrister, and judge, Sir William Grove. In recent decades, however, researchers have been intermittently excited by another possibility-that of exploiting microbial metabolism as a potentially inexhaustible source of electricity. One method, the so-called indirect device, simply uses bacteria to produce a fuel such as hydrogen as one of the reactants in an otherwise conventional cell. With Clostridium butyricum as his work-horse, Professor Shuichi Suzuki and a team at the Tokyo Institute of Technology have designed cells of this sort, and they work reasonably well. But the challenge remains of tapping directly the electric currents produced by microorganisms as they grow and oxidize foodstuffs.

The idea is simple enough-microbial respiration generates a copious supply of electrons, which might in theory be passed to the anode of a fuel cell and thence to an external circuit, linked in turn back to the fuel cell's cathode. Several groups have reported modest success in achieving such a flow of electrons, and thus current, from bacteria. But all have been thwarted by one formidable barrier. The bacterial cell wall screens respiratory processes, located in the underlying cell membrane, from the fuel cell anode. So only a meager diffusion of electrons is possible. Currents have been far too weak to be of any practical value.

A solution to the problem began to emerge a few years ago when Dr. Bennetto and his London colleagues, together with Dr. Kazuko Tanaka at the the Institute of Physical and Chemical Research in Saitama, south of Tokyo, decided to study the potential value of certain dyes in biotechnology. They chose the "redox" dyes, colored when oxidized and colorless when reduced, which are commonly used as stains to visualize organisms and as indicators when testing for bacterial contamination in milk and foods. Because microorganisms could reduce these agents by donating electrons to them, they speculated, it might be possible to exploit them as carriers for ferrying electrons across the cell wall. If so-and the idea hinged upon whether the wall was permeable to dyes in both their reduced and oxidized forms-then they might find a variety of applications in biotechnology.

Collaboration between London and Tokyo soon indicated excellent prospects. Studies with 12 different organisms and redox dyes such as methylene blue, thionine, and toliudine blue confirmed that all but one reduced many of the dyes. Moreover, several of the dyes did play the role of mediators, as predicted, coupling microbial respiration with the anode of a fuel cell. When the experimenters drew electric current from the cell, the mediator became re-oxidized and travelled back through the cell wall to be reduced once again. The net result was akin to a chain of countless buckets, ferrying electrons across and otherwise virtually unbridgeable gulf.

Having established the soundness of the principle, the Queen Elizabeth College researchers decided to survey systematically the principal factors affecting the output from such a direct microbial fuel cell. As described in two papers in the Journal of Chemical Technology and Biotechnology $(1984,34 B: 3$ and 13), they have now gone a long way towards identifying the most effective combinations of organisms, redox mediators, and substrates for microbial growth (as well as materials for construction of the anode and cathode). They have also satisfied themselves that long-term instability of the organisms-a potential restriction on practical applications of fuel cells-does not threaten to limit them seriously in practice. Devices using Escherichia coli fed on lactose, for example, have run continuously for up to three months, generating steady currents of $0.8 \mathrm{~mA}$ without any decline in bacterial activity. As with other biotechnological processes, this stability might well be improved further by immobilizing the cells.

The most promising performance overall came from a fuel cell using the bacterium Proteus vulgaris growing with glucose as substrate and thionine as electron mediator. This registered currents of over $1.0 \mathrm{~A}$ at $0.3 \mathrm{~V}$ for short periods of time, while being capable of sustaining more than $100 \mathrm{~mA}$ at a lower voltage for several hours. Gerard Delaney and his colleagues believe that microbial fuel cells delivering several watts of power may be feasible in the near future. Devices of this sort could, they suggest, find many practical applications, such as meeting low power requirements in remote areas and providing for on-site processing of waste materials.

True, the Queen Elizabeth College research has also revealed problems and areas of ignorance. Thionine, for example, is less stable than is desirable for long-term use. And more needs to be known about the way(s) in which microorganisms interact with electron mediators. But the Science and Engineering Research Council, which finances the work, will no doubt see such questions as scope for further improvement rather than as serious demerits. The year 1984 could well be the end of the beginning for the microbial fuel cell.

Bernard Dixon, Ph.D., is a microbiologist and regular columnist for BIO/TECHNOLOGY. He is a former editor of New Scientist. 